\title{
Emerging Antibacterial Strategies with Application of Targeting Drug Delivery System and Combined Treatment
}

\author{
Wenli Zhang ${ }^{1, *}$ \\ Enshi Hu',* \\ Yajie Wang ${ }^{1} *$ \\ Si Miao' \\ Yanyan Liu' \\ Yumin $\mathrm{Hu}$ III \\ Ji Liu' \\ Bohui Xu (iD) ${ }^{2}$ \\ Daquan Chen (iD) ${ }^{3}$ \\ Yan Shen (1D) \\ 'Department of Pharmaceutics, China \\ Pharmaceutical University, Nanjing, \\ 210009, People's Republic of China; \\ ${ }^{2}$ School of Pharmacy, Nantong University, \\ Nantong, 22600I, People's Republic of \\ China; ${ }^{3}$ School of Pharmacy, Yantai \\ University, State Key Laboratory of Long- \\ acting and Targeting Drug Delivery \\ System, Yantai, 264005, People's Republic \\ of China
}

*These authors contributed equally to this work
Correspondence: Yan Shen; Daquan Chen Tel +86-25-8327l 305; +86-535-670602I Email shenyan@cpu.edu.cn; cdq1981@I26.com

\begin{abstract}
At present, some bacteria have developed significant resistance to almost all available antibiotics. One of the reasons that cannot be ignored is long-term exposure of bacteria to the sub-minimum inhibitory concentration (MIC) of antibiotics. Therefore, it is necessary to develop a targeted antibiotic delivery system to improve drug delivery behavior, in order to delay the generation of bacterial drug resistance. In recent years, with the continuous development of nanotechnology, various types of nanocarriers that respond to the infection microenvironment, targeting specific bacterial targets, and targeting infected cells, and so on, are gradually being used in the delivery of antibacterial agents to increase the concentration of drugs at the site of infection and reduce the side effects of drugs in normal tissues. Here, this article describes in detail the latest research progress on nanocarriers for antimicrobial, and commonly used targeted antimicrobial strategies. The advantages of the combination of nanotechnology and targeting strategies in combating bacterial infections are highlighted in this review, and the upcoming opportunities and remaining challenges in this field are rationally prospected.
\end{abstract}

Keywords: nanocarriers, antimicrobial, drug delivery, targeting strategies

\section{Introduction}

The infection is still considered as one of the most challenging natural threats to which humans are exposed. Broad-spectrum antimicrobials used to be the most common therapy to achieve a certain control on infections. However, increased resistance against antibiotics makes infection difficult to eradicate.

Admitted, abuse of antibiotics is still the primary factor of drug resistance. Apart from this, sub-minimum inhibitory concentration (MIC) is also considered as a non-negligible factor. If bacteria are exposed to the sub-MIC environment for a long time, some bacteria may produce drug-resistant mutations and promote horizontal transfer of antibiotic resistance genes; ${ }^{1-5}$ not only this, low-level antibiotics can significantly induce biofilm formation, making the MIC level rise even more sharply. ${ }^{6}$

However, the MIC level is not as easy to achieve as expected, which mainly occurred in the following three different circumstances. (1) The physiological and drug effects, such as blood flow, vascular permeability, drug physical and chemical properties, and drug affinity to the tissue, could make the distribution of drug to certain infected tissues difficulty. (2) Bacteria phagocytosed by macrophages may 
be protected from the host's immune system and survive intracellularly. However, only limited antibiotics could be delivered across the cell membrane, which was under MIC to inhibit the intracellular bacteria. (3) In addition to planktonic cells, bacteria that colonize living surfaces that are altered by certain damage typically form biofilms, in which those bacteria are attached to the substratum or each other and embedded in the extracellular matrix. ${ }^{7}$

In order to achieve or maintain the MIC, nanocarrier with certain strategies has become a research hotspot, which could improve the drug concentration in local targeted sites or inside the cells. This review would summarize different kinds of nanocarriers including several abiotic nanocarriers (liposomes, nanoparticles, conjugate, etc.) and biological biocarriers (adenovirus, lysozyme) to realize targeting strategies that indicates an effective direction for treatment (Figure 1), and focus on three major aspects of targeting strategies:(1)targeting bacteria, (2)responding to the microenvironment altered by pathogens, (3)targeting bacterially infected cells (Table 1). Although most vectors we summarized do not have antibacterial activity, they can also target infection or response environmental change through the modification of ligands or functional groups, so as to achieve local drug release beyond the MIC. At the same time, we also summarized partial antibacterial active carriers, and their combined application with antibiotics is an effective way to solve bacterial resistance.

More importantly, this review systematically summarizes drug-targeted delivery strategies based on bacterial targets and hopes that the carriers are more than just the precise delivery of antibiotic, and has certain universality: that is, a delivery strategy can be applied to a certain class or species of bacteria with the same or similar targets.

\section{Targeting by Microenvironmental Excitation}

In view of the fact that certain bacteria colonize the internal environment of the human body, they also change the surrounding microenvironment, which may cause certain inflammatory reactions. Some bacteria can reduce the local $\mathrm{pH}$ value of infected tissues through anaerobic fermentation triggered by hypoxia, and host immune response can further reduce the local $\mathrm{pH}$ value of bacterial sites through the mechanism of lactic acid production during the process of phagocytosis. In addition, certain bacteria excrete enzymes during growth and reproduction, which is also the key to responsive drug delivery systems. Therefore, researchers can design targeted, controlled-release intelligent drug delivery systems, which can be used to treat diseases caused by bacterial infection.

\section{Utilizing Changes in $\mathrm{pH}$ to Specifically Release Drug}

Bacterial growth produces acidic metabolites such as acetic acid, lactic acid and carbon dioxide due to hypoxic conditions, causing decrease in $\mathrm{pH}$ and increase in acidity. A kind of drug delivery system that specifically releases at the site of infection can be designed based on this $\mathrm{pH}$ change. $^{8,9}$ For instance, surface-charge-converting polymer-based nanoparticles (NPs) are designed to target bacterial cell walls, this vector has no targeting ability at $\mathrm{pH}$ 7.4 , but strongly adheres to the bacterial surface at acidic $\mathrm{pH}$ and subsequently delivers the antimicrobial drug. The poly (D, L-lactic acid-co-glycolic acid)-b-poly (L-histidine)-poly (ethylene glycol) (PLGA-PLH-PEG) NPs undergo surface charge conversion by selective protonation of the imidazole group of PLH at low $\mathrm{pH}$. The NPs do not have the targeting ability at $\mathrm{pH}=7.4$. When acidic, the PLH segment will be positively charged. This charge transfer promotes a strong electrostatic bond between NPs and bacteria due to negatively charged bacterial cell walls. ${ }^{9}$ At the same time, another means is polyelectrolyte multilayer (PEM) coating. PEM coating is composed of cationic antibiotics with tannic acid (TA), for which the films allow the effective retention of antibiotics at $\mathrm{pH}$ 7.4. During the growth of bacteria, such as the Staphylococcus epidermidis ( $S$. epidermidis) or Escherichia coli (E. coli), which are capable of, respectively, producing lactic acid and acetic acid, $\mathrm{pH}$ begins to decrease and the electrostatic interaction between the layers gradually disappears, resulting in the selective release of the antibiotic. ${ }^{10,11}$

The treatment of Helicobacter pylori (H. pylori) is an important challenge. The reason is that the bacteria locate in the inner layer of gastric mucus, so that drug delivery needs to overcome highly acidic gastric environment. A novel pH-responsive gold nanoparticle-stabilized liposome was designed. Small chitosan-modified gold NPs are adsorbed onto the outer surface of the negatively charged phospholipid liposomes. The nanoparticle stabilizers were found to cause lipid surface remodeling at the point of adsorption of the NPs, reducing the surface tension of the liposomes and further enhancing the stability of the liposomes. It has been well documented that the $\mathrm{pH}$ in the 


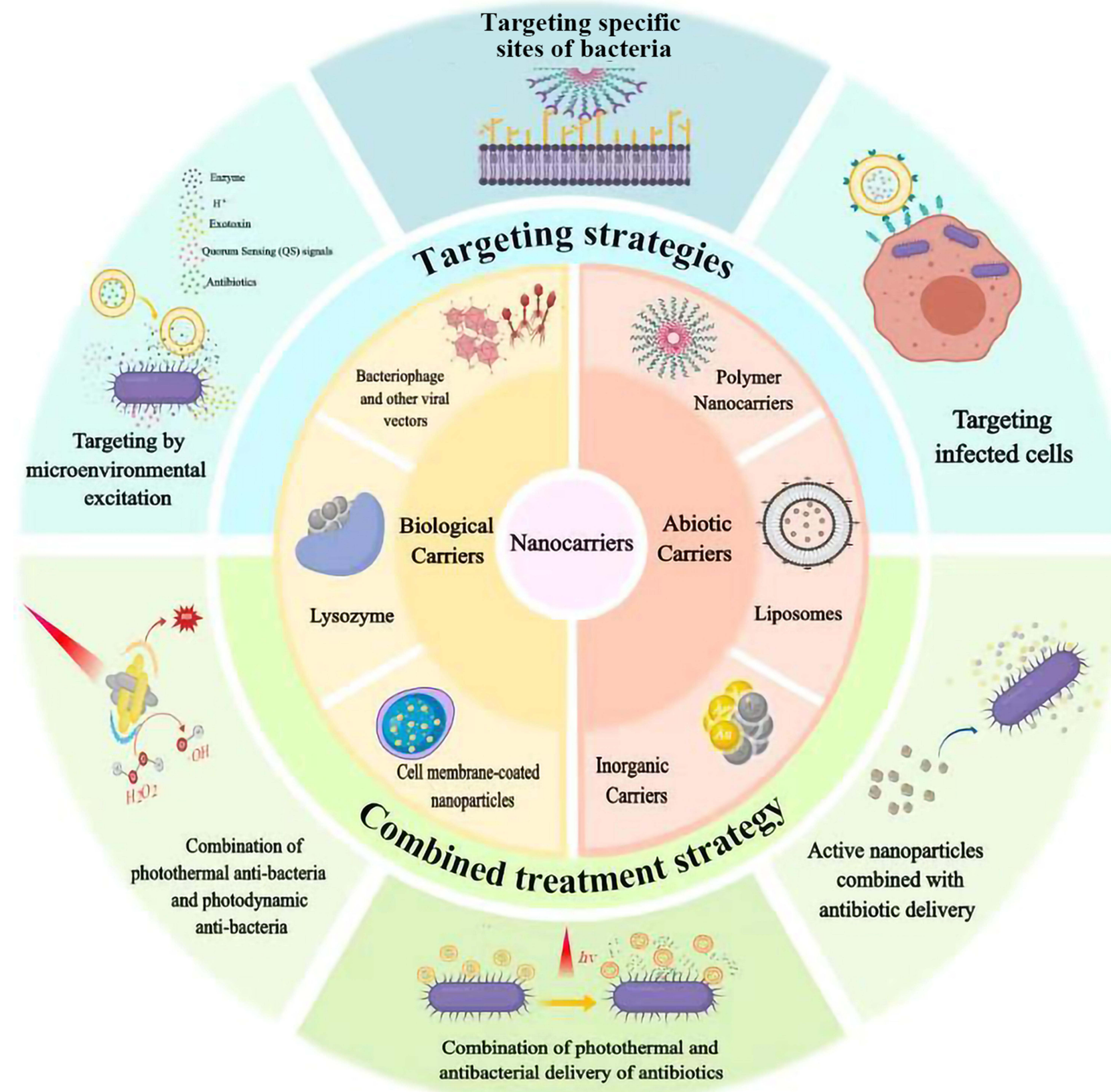

Figure I The targeted and combined strategies for antibacterial treatment with application of abiotic and biological nanocarriers.

gastric mucus layer ranges from $\mathrm{pH}=1.2$ in gastric acid to $\mathrm{pH}=6.0$ in the gastric mucosa to $\mathrm{pH}=7.4$ in $H$. pylori colonized epithelial cells. ${ }^{12,13}$ Liposomes are stable at gastric $\mathrm{pH}$, when stable liposomes are present in a near neutral $(\mathrm{pH}=7.4)$ environment, gold stabilizers are separated from the liposomes and freed by reducing the high surface tension of the liposomes. Liposomes can be actively fused with bacterial membranes. ${ }^{13}$

Cysteine-bound chitosan, derivative-thiolated chitosan (Cys-CS), has mucoadhesive and anticoagulant functions.
Cys-CS/PMLA nanoparticles were prepared from positively charged chitosan and negatively charged PMLA. And the zeta potential of these nanoparticles were positive, so they can interact with the negative cell wall of the bacteria. Therefore, the effects of Cys-CS and PMLA can be utilized to prepare multifunctional NPs that specifically target and decompose bacterial membranes. The results showed that amoxicillin-Cys-CS/PMLA NPs have good $\mathrm{pH}$-sensitivity, can prevent the release of amoxicillin in gastric acid, and make the drug adhere to the gastric 
Table I Summary of the Antibacterial Strategies

\begin{tabular}{|c|c|c|c|}
\hline Strategies & Targets & Nanovectors & Bacteria \\
\hline \multirow[t]{8}{*}{ Microenvironmental excitation } & \multirow[t]{4}{*}{ Changes in $\mathrm{pH}$} & Surface-charge-converting NPs & $\mathrm{G}^{+}(\mathrm{S}$. aureus $)$ \\
\hline & & Polyelectrolyte multilayer film coating & S. epidermidis; E. coli \\
\hline & & Gold nanoparticle-stabilized liposome & \multirow[t]{2}{*}{ H. pylori } \\
\hline & & Amoxicillin-Cys-CS/PMLA NPs & \\
\hline & \multirow[t]{2}{*}{ Enzymatic hydrolysis } & Amylase: Drug-dextrin conjugates & $\begin{array}{l}\mathrm{G}^{-}(\text {A. baumannii; A. Iwoffi; E. coli; } \\
\text { K. pneumoniae; P. aeruginosa) }\end{array}$ \\
\hline & & $\begin{array}{l}\text { Phospholipases and lipase: PLA2 responsive } \\
\text { liposomes }\end{array}$ & H. pylori \\
\hline & \multirow[t]{2}{*}{ Exotoxin } & Gold nanoparticle stabilized-liposomes & Methicillin-resistant S. aureus \\
\hline & & Mesoporous silica NPs & $\mathrm{G}^{+}(\mathrm{S}$. aureus $)$ \\
\hline \multirow[t]{5}{*}{ Bacterial specific targets } & Carbohydrates & Lectin conjugated gliadin NPs & H. pylori; S. epidermidis; $P$. vulgaris \\
\hline & \multirow[t]{2}{*}{ Lipopolysaccharide } & Molecularly imprinted NPs & $\mathrm{G}^{-}(P$. aeruginosa $)$ \\
\hline & & AMP-LPS binding peptides hybrid peptides & $\mathrm{G}^{-}($E. coli; S. typhimurium $)$ \\
\hline & Bacterial envelop & Lysozyme @ antibiotic & $\begin{array}{l}\mathrm{G}^{+}(\text {S. aureus; S. epidermidis; } \\
\text { S. zooepidemicus; M. luteus }) / \mathrm{G}^{-}(E . \text { coli; } \\
\text { K. pneumoniae; P. aeruginosa; S. typhimurium })\end{array}$ \\
\hline & Specific protein & AMX-PLGA/UCCs-2 NPs & H. pylori \\
\hline \multirow[t]{6}{*}{ Infected cells } & Arginine & Arg-MSN NPs & Mycobacterium; Salmonella \\
\hline & \multirow[t]{3}{*}{ Mannose receptors } & Mannosylated liposomes & L. donovani \\
\hline & & Mannose-anchored SLNs & Tubercle bacillus \\
\hline & & Mannosylated nanogel & Methicillin-resistant S. aureus \\
\hline & Enhance macrophage uptake & Sterically stabilized liposomes & Mycobacterium \\
\hline & $\begin{array}{l}\text { Transfection of macrophages with } \\
\text { viruses }\end{array}$ & $\begin{array}{l}\text { Recombinant adenovirus @ Hybrid AMP } \\
\text { CAMA-syn encoding gene }\end{array}$ & $\mathrm{G}^{+} / \mathrm{G}^{-}$ \\
\hline \multirow[t]{12}{*}{ Combined treatment } & \multirow{6}{*}{$\begin{array}{l}\text { Active nanovectores and } \\
\text { antibiotic }\end{array}$} & SA liposomes & \multirow{2}{*}{$\begin{array}{l}\mathrm{G}^{+}(\mathrm{S} \text {. epidermidis; methicillin resistant } \\
\text { S. aureus) }\end{array}$} \\
\hline & & PI-DPPG liposomes & \\
\hline & & MSN\& silver @ levofloxacin & Multidrug-resistant $E$. coli \\
\hline & & Vancomycin-terminated AuNPs & Vancomycin-resistant Enterococci; E. coli \\
\hline & & $\mathrm{TiO} 2-\mathrm{Ag} \mathrm{NPs}$ & C. albicans; A. albicans \\
\hline & & Peptide-like oligomers & $\mathrm{G}^{+}(\mathrm{S}$. aureus $)$ \\
\hline & \multirow{4}{*}{$\begin{array}{l}\text { Photothermal \& photodynamic } \\
\text { antibacterial }\end{array}$} & Au-Ag core-shell NPs & S. aureus \\
\hline & & PDA@Au-Hap & S. aureus; E. coli \\
\hline & & PEDOT: ICG @ PEG-GTA NPs & S. aureus; E. coli \\
\hline & & Fe3O4@ PDA NPs & S. aureus; E. coli \\
\hline & \multirow[t]{2}{*}{$\begin{array}{l}\text { Photothermal \& delivery of } \\
\text { antibiotics }\end{array}$} & $\begin{array}{l}\text { Gold nanocage @ daptomycin @ } \\
\text { staphylococcal protein antibodies }\end{array}$ & S. aureus \\
\hline & & $\begin{array}{l}\text { Near infrared activated thermosensitive } \\
\text { liposomes }\end{array}$ & P. aeruginosa \\
\hline
\end{tabular}


mucosa, increasing the residence time of the stomach for the target. At the site of $H$. pylori infection, the prepared NPs become unstable and disintegrate due to its $\mathrm{pH}$ sensitivity, and then the antibiotics are released locally and act on $H$. pylori. ${ }^{12}$

\section{Using Enzymatic Hydrolysis to Release Drugs}

Bacteria can produce enzymes to maintain normal life activities. The invasive enzymes produced by microorganisms are associated with their pathogenicity. Although most of them are intracellular enzymes, and bacteria can also produce extracellular enzymes, such as proteases, amylases, and cellulases. Most of the extracellular enzymes are hydrolases, which can degrade macromolecular substances into small molecular substances to make use of by microorganisms.

Therefore, according to this strategy, a drug delivery system based on an enzyme response carrier can be designed to realize the targeting of infected sites. Since bacteria can secrete amylase, dextrin was designed as a polymer carrier to carry colistin to the site of infection. ${ }^{14}$ Therefore, by using Polymer masked -unmasked protein therapy (PUMPT), the polymer binds to the drug to "mask" the protein or peptide, allowing it to hydrolyze at a specific site of infection. As a kind of polymer, dextrin has strong water solubility and is easily degraded by amylase to produce maltose $(\alpha-1,4)$ and isomaltose $(\alpha-1,6)$. At the same time, it can be modified by functional groups (such as succinoylation), so as to effectively load antibiotics and "mask" the activity. And the degradation of dextrin by $\alpha$ amylase allows the local environment to trigger the recovery of drug activity. More importantly, succinoylation will change the rate of dextrin degradation, thereby controlling antibiotics release rate. Therefore, succinylated dextrin could combine with colistin to form dextrin-colistin conjugates, which are bound via 3 primary amino groups. Amylases secreted by bacteria will destroy the conjugates' glycosidic bonds, forming oligosaccharides and/or maltose linked colistin. Exposed cationic amine groups on colistin play an important role in the interaction of colistin with bacterial lipopolysaccharides ${ }^{15,16}$.

Similarly, besides amylase, phospholipases and lipase can also be used as the keys to stimulate carriers. It is known that $H$. pylori can secrete phospholipid A2 (PLA2).
This enzyme is capable of hydrolyzing membrane phospholipids, causing mucosal damage and facilitating bacterial survival. At the same time, PLA2 can destroy membrane integrity, allowing the payload liposomes to be triggered and release antibiotics. Therefore, it has been studied to synthesize PLA2 responsive liposomes from PLA2-responsive lipids and stabilize them with small chitosan-modified gold NPs. When the stabilized liposomes are located near the $H$. pylori bacteria, the PLA2 secreted by the bacteria will hydrolyze the phospholipid, impair membrane integrity, and release the drug. What is more, the higher the PLA2 concentration, the more the drug will be released. ${ }^{4}$ In addition, the use of a lipase-sensitive polymer triple-layered nanogel (TLN) as drug carriers to accurately carry antibiotics is also being investigated. Its exterior has a hydrophobic poly(epsiloncaprolactone) (PCL) chain to surround the polyphosphate core, preventing the antibiotic from reaching the site of infection from the polyphosphate core. Once the TLN senses lipase-secreting bacteria, the PCL "fence" of the TLN is degraded to release antibiotics. ${ }^{17}$

\section{Using Exotoxin to Release Antibiotics}

The bacterial exotoxin is mainly a toxic protein produced by gram-positive bacteria in the course of living, which can be secreted into the body or released after the cell is broken. The exotoxin usually consists of two subunits (the toxic unit and the receptor-binding unit). It can be divided into neurotoxins, cytotoxins and enterotoxins, and expresses toxicity in several different ways, such as destroying target membrane integrity, inhibiting target cell protein synthesis, and blocking neurotransmitter release. Typically, the toxin is inserted into the host cell membrane, resulting in the formation of transmembrane pores. ${ }^{18,19}$ At the same time, different bacterial toxins own the same characteristic, that is, the toxin protein undergoes a conformational transition under the induction of acidic $\mathrm{pH}$, exposing the hidden hydrophobic domain. This facilitates the incorporation of the toxin into the cell membrane and translocation into the cytoplasm in whole or in part. ${ }^{20}$ This conformational transition promoted by acidic $\mathrm{pH}$ allows the protein to penetrate into the hydrophobic core of the lipid, helping to form pores. According to this principle, the toxins secreted by the target bacteria can then be utilized and used to trigger the release of the therapeutic payload, thereby killing the bacteria.

Therefore, some researchers have designed a kind of gold nanoparticles stabilized-liposome triggered by 
bacterial toxin. The drug is protected by the nanocarriers and will not be released. Only when the bacterial toxin activates the liposome, the drug is selectively released at the site of bacterial infection. The binding of chitosanmodified gold NPs to the surface of the liposomes can effectively prevent the liposomes from merging with each other and slow the release at non-infected parts. When the liposomes are transported to the site of infection, the secreted toxin will be inserted into the liposome membrane and form a pore through which the antibiotic is released, allowing the location to reach a high drug concentration. ${ }^{21}$ Similarly, according to the same principle, some researchers have designed mesoporous silica nanoparticles (MSNs) with bacterial toxins-responsive lipid bilayer surface shells. The lipid material prevents drug release from MSNs and can be degraded by bacterial toxins at the site of infection to rapidly release the drug, thereby achieving effective bacterial inhibition. ${ }^{22}$

\section{Targeting Specific Sites of Bacteria}

As a complete organism, bacteria have a variety of specific antigens on their cell surface, such as specific proteins, polysaccharides, lipopolysaccharides, teichoic acid and even cell membranes or cell walls. These antigens can be recognized and combined by their ligands, so they provide a good idea for targeted drug delivery.

\section{Targeting Carbohydrates on Bacterial Cell Walls}

Lectins can bind to microorganisms containing simple or complex carbohydrates, and the cell wall of $H$. pylori in the stomach has mannose and fucose residues, so the specific lectin can produce strong agglutination with the corresponding mannose and fucose. ${ }^{23}$ Therefore, based on this principle, fucose-specific Ulex Europaeus Agglutinin I (UEA I) and mannose-specific Concanavalin A (Con A)lectins (site-specific) conjugated gliadin nanoparticles (stomach diapause) were designed to deliver drugs in $H$. pylori and binding to its carbohydrate receptor for the treatment of H. pylori infection. The gliadin composition contains neutral and lipophilic residues-neutral amino acids can promote interaction with mucous membrane hydrogen bonds, while lipophilic components can interact with biological tissues through hydrophobic interactions, which can enhance adhesion and retention in the gastric mucosa. Gliadin nanoparticles (GNPs) show strong tropism in the upper digestive tract area. These vectors are capable of targeting and avoiding degradation of the loaded drug. Experiments have shown that UEA I-GNPs and Con A-GNPs have significantly the ability to inhibit bacteria compared to GNPs, and the efficacy is about twice as high. ${ }^{24}$ At the same time, lectins are also used in many other bacterial infections, and Con A has been found to selectively bind to alpha-mannan and alphaglucopyranosyl residues in the extracellular polysaccharide matrix of many biofilms. ${ }^{25}$ Therefore, succinylated Con A (sCon A)-bearing liposomes were designed to deliver triclosan to biofilms of skin-associated bacteria, such as Staphylococcus epidermidis and common Proteus vulgaris et al. ${ }^{25,26}$

\section{Targeting Lipopolysaccharide}

Among gram-negative bacteria, lipopolysaccharide (LPS), is a unique component consisting of lipid A, core polysaccharide, and polysaccharide $\mathrm{O}$ antigen. Among them, the lipid A is a kind of glycolipid compound composed of a pyrophosphate bond by esterified glucosamine disaccharide units, which has a pyrogenic effect and is a toxic component of gram negative $\left(\mathrm{G}^{-}\right)$bacterial endotoxin. LPS is the main component of $\mathrm{G}^{-}$bacterial endotoxin and determines the diversity of $\mathrm{G}^{-}$bacterial surface antigenic determinants. Therefore, LPS can be used as a target to design a variety of strategies for the treatment of $\mathrm{G}^{-}$ bacterial infections.

For strategies targeting LPS, a ligand-free targeted DDS is currently available, with molecular imprinting being a newly developed strategy with highly stable drug carriers, which own ligand-like "cavities". The polymeric carrier can be prepared by inverse microemulsion polymerization, and in this process, the template macromolecule is embedded on the NPs surface and then dialyzed to remove the template molecule to produce a binding site with strong affinity for the target. ${ }^{27-30}$ According to this strategy, molecularly imprinted nanoparticles (MIPNP) using pseudomonas aeruginosa (P. aeruginosa) amphiphilic LPS as a template for imprinting were designed. Since LPS has amphiphilic properties, it can prepare synthetic spherical NPs by inverse microemulsion polymerization using LPS as a natural template, and the molecular cavity or motif specific to LPS is imprinted on this NP. The ability of NPs with LPS cavities to specifically bind to $P$. aeruginosa was shown by fluorescence polarization and microscale thermophoresis. ${ }^{27}$

In fact, for the treatment of multidrug-resistant (MDR) bacteria and $\mathrm{G}^{-}$bacteria that are not sensitive to common 
antibiotics, antimicrobial peptides (AMPs) isolated from organisms provide a new therapeutic approach, ${ }^{31,32}$ especially design-specific hybrid peptides that act as a specific targeted AMP (STAMP) to specifically deliver the drug at the site of infection. The focus of this strategy is on the construction of fusion peptides that use a segmental flexible linker to combine the targeting domain with the bactericidal domain; the targeting domain confers selectivity to the killing domain by binding to the pathogen using specific determinants on the surface of the pathogen. In this experiment, LPS was used as a target, various LPS binding peptides were added to design hybrid peptides and analyzed to evaluate the selectivity of hybrid peptides for $\mathrm{G}^{-}$bacteria and the binding and neutralizing activity of LPS. According to the MIC test, the MIC range of the hybrid peptide was 0.5 to $4 \mu \mathrm{M}$, indicating that the hybrid peptides modified by LPS targeting peptide [amino acids 28-34 of lactoferrin (Lf 28-34), amino acids 84-99 of bactericidal/permeability increasing protein (BPI84-99)]Lf-GUN7 and BPI-GUN7-designed by this strategy showed strong antibacterial activity against both grampositive and $\mathrm{G}^{-}$bacteria with little cytotoxicity. ${ }^{33}$

\section{Targeting Bacterial Envelope}

The bacterial cell envelope is a complex multi-layered structure consisting of the cytoplasmic membrane, cell walls and the outer membrane of $\mathrm{G}^{-}$bacteria, which are used to protect bacterial microorganisms from adverse environmental effects, trigger immune responses and participate in immune escape. The cell envelope of most bacteria is divided into two main categories. Among them, the cell wall of the gram-negative bacterial peptidoglycan (PG) is thin, and there is an outer membrane containing lipopolysaccharide outside the cell wall. Although the gram-positive bacteria have no outer membrane, they are surrounded by a large number of peptides and have a long anionic polymer-phosphate wall acid. This can be used to design a drug delivery strategy targeting the envelope. $^{34,35}$

Lysozyme in egg albumin can be utilized to facilitate targeting of phenolic antimicrobial agents. Lysozyme kills sensitive bacteria by degrading the glycoside b-bond between the $\mathrm{N}$-acetylhexosamines of the peptidoglycan layer in the bacterial cell wall. Although lysozyme can be recognized by LPS on the outer membrane of gramnegative bacteria, lysozyme is limited to killing certain gram-positive bacteria. ${ }^{36}$ Therefore, a strategy for specifically delivering a poorly soluble antimicrobial drug to a bacterial envelope by using a lysozyme as a carrier to load a drug into the hydrophobic core of lysozyme is derived. The drug-loaded lysozyme is recognized by the LPS or PG on the surface of the bacterial cell and interacts with the bacterial cell envelope to release the antibiotic it carries into the microbial cell. ${ }^{37}$

\section{Targeting Specific Protein}

It has been found that $H$. pylori can specifically express Urea Transport protein (Urel), ${ }^{12,13}$ which can carry urea to the cytoplasmic urease. ${ }^{12}$ Chemical urease can hydrolyze urea into ammonia and bicarbonate to neutralize the acidic $\mathrm{pH}$ of the stomach environment and form a beneficial environment for $H$. pylori. So, it can be used as a target. Therefore, the urea-modified chitosan derivative ureido-conjugated chitosan (UCCs-2) can be used as a targeting part of the vector combined with UreI of $H$. pylori, so $\mathrm{pH}$-sensitive amoxicillin-loaded AMX-PLGA/UCCs-2 anti-H. pylori nanoparticles were constructed. The results show that the NPs have good pH sensitivity, low cytotoxicity, strong specificity and good antibacterial properties. The drug is more efficiently delivered to the site of infection to target eradication of H. pylori than non-targeted AMX-PLGA/UCCs antiH. pylori NPs. ${ }^{38,39}$

\section{Targeting Infected Cells}

Intracellular bacteria, especially Mycobacterium tuberculosis, Salmonella, Staphylococcus aureus (S. aureus), are important pathogenic microorganisms that pose a serious threat to human health. Killing intracellular bacteria is the key to effective treatment. And macrophages are one of the most susceptible to infection. In some cases, macrophages can protect microbes and even supply important nutrients. Bacteria phagocytosed by macrophages can survive in these cells and protect them from the immune system and antibiotics, which can lead to infection relapse or chronic inflammation. ${ }^{40,41}$

Most antibiotics have poor permeability to cells and have reduced intracellular activity, so they may be difficult to effectively inhibit intracellular infection. Not only that, many intracellular bacteria are dormant, causing some drug targets to down-regulate, cell membrane permeability to decrease, and reducing the sensitivity of bacteria to antibiotics. ${ }^{42}$ However, some changes in macrophages biological traits may become the key to being targeted by nanocarriers. The nanocarriers could be taken by the 
macrophages and release the active ingredients once they are ingested by macrophages.

\section{Arginine Based Nanocarriers for Targeting}

In macrophages, Salmonella forms a protective membrane called Salmonella containing vacuole (SLV), in which it is able to obtain nutrients from the host for survival and replication. Studies have shown that the bactericidal concentration required to eliminate intracellular bacteria is higher than the bactericidal concentration of extracellular bacteria due to poor permeability of intracellular antibiotics.

It is also known that other intracellular pathogens (Legionella, Brucella, Francisella and Shigella) can scavenge several amino acids such as arginine (Arg) from host cells and even cause severe amino acid starvation. Arginine is an important cellular immune response modulator for macrophages, and nitric oxide (NO) is one of the mediators produced by arginine and responsible for the cytotoxic activity of macrophages against intracellular pathogens. There are two pathways for the host to utilize arginine, one that is mediated by nitric oxide synthase to form NO, and the other that is arginase-mediated to form ornithine and urea. Mycobacterial-infected cells showed increased uptake of arginine by cation transporters (CAT1 and CAT2), and more arginine utilization was transferred to the arginase pathway, resulting in decreased production of antimicrobial nitric oxide. Salmonella infection also causes upregulation of the CAT1 transporters, resulting in increased arginine uptake, and it was observed that the CAT1 transporters were recruited into SCV. Therefore, due to the increased absorption of arginine by infected macrophages, an arginine-based nanocarrier system (Arg-MSN) was developed, which was used on mesoporous silica nanoparticles (MSN) templates. ${ }^{43}$

\section{Targeting Mannose Receptors on Macrophages}

Recent studies have shown that mannose receptors are present on the surface of macrophages, and based on this, mannosylated liposomes are designed to selectively enhance the uptake of chemistry drugs (ciprofloxacin) or certain natural medicines (andrographolide) by macrophages in vivo after administration. ${ }^{44-46}$ In another study, mannoseanchored solid lipid nanoparticles were designed to selectively deliver anti-tuberculosis drugs (rifabutin) to alveolar macrophages. In vitro cell uptake showed a six-fold increase in alveolar macrophage internalization by mannose binding. After 24 hours of dosing, free rifabutin was mainly distributed in the kidneys at the early stage and finally distributed in the lungs and liver, while mannose-anchored rifabutin nanoparticles were mostly distributed in the lungs. ${ }^{47}$ Although the uptake of mannosylated liposomes by alveolar macrophages (AMs) was significantly increased, at the same time free mannose significantly inhibited the uptake of mannosylated liposomes, suggesting that the uptake mechanism of AMs on mannosylated liposomes is mannose receptormediated endocytosis. ${ }^{48}$ Since the availability of mannose receptors is a factor in the efficient uptake of mannosylated liposomes, it is necessary to determine the optimal ratio of mannosylation that can be used to provide effective macrophage targeting. ${ }^{48,49}$

The mannose receptor is expressed in AMs, and the surfactant protein (SP) in the epithelial lining fluid (ELF) upregulates the activity of the mannose receptor of AMs. Studies have shown that uptake of mannosylated liposomes by phagocytic cells is accelerated by conditioning based on complement activation. Since SP-A and SP-D have similar ultra-structures to mannose-binding proteins, SP-A and SP-D have high affinity for mannose. While SPA and SP-D can bind to the mannose receptor and SP receptor of AMs, the uptake of mannosylated liposomes by mannose receptors and SP receptors is increased. ${ }^{48}$

Another application is a mannosylated nanogel drug carrier, and this nanocarrier can undergo undergoes degradation by bacterial enzymes to release the drug. The nanogel of the polyphosphate crosslinked core and the PEGylated shell modified with the mannosyl ligand can be degraded by bacterially produced active phosphatase or phospholipase (Figure 2A). ${ }^{41}$ Mannosylated nanogels can target antibiotics for macrophages: macrophages express high levels of mannose receptors for uptake of mannosylated nanogels (Figure 2B) and macrophage transport into bacterial infection sites to increase drug accumulation. At the site of infection, macrophages further ingest bacteria, and the degradation of the polyphosphate core containing drugs is initiated by active phosphatase or phospholipase produced by the bacteria. Thus, the nanogel provides macrophage targeting and activatable drug release properties. ${ }^{1}$ Nanogels are internalized in endosomes or early lysosomes and are in tight vicinity to bacteria in phagosomes or phagolysosomes. Since the above vacuoles can be incorporated into macrophages, the nanogel can be triggered by microbial enzymes and endolysosomal enzymes to release the drug. ${ }^{41}$ Nanogels 


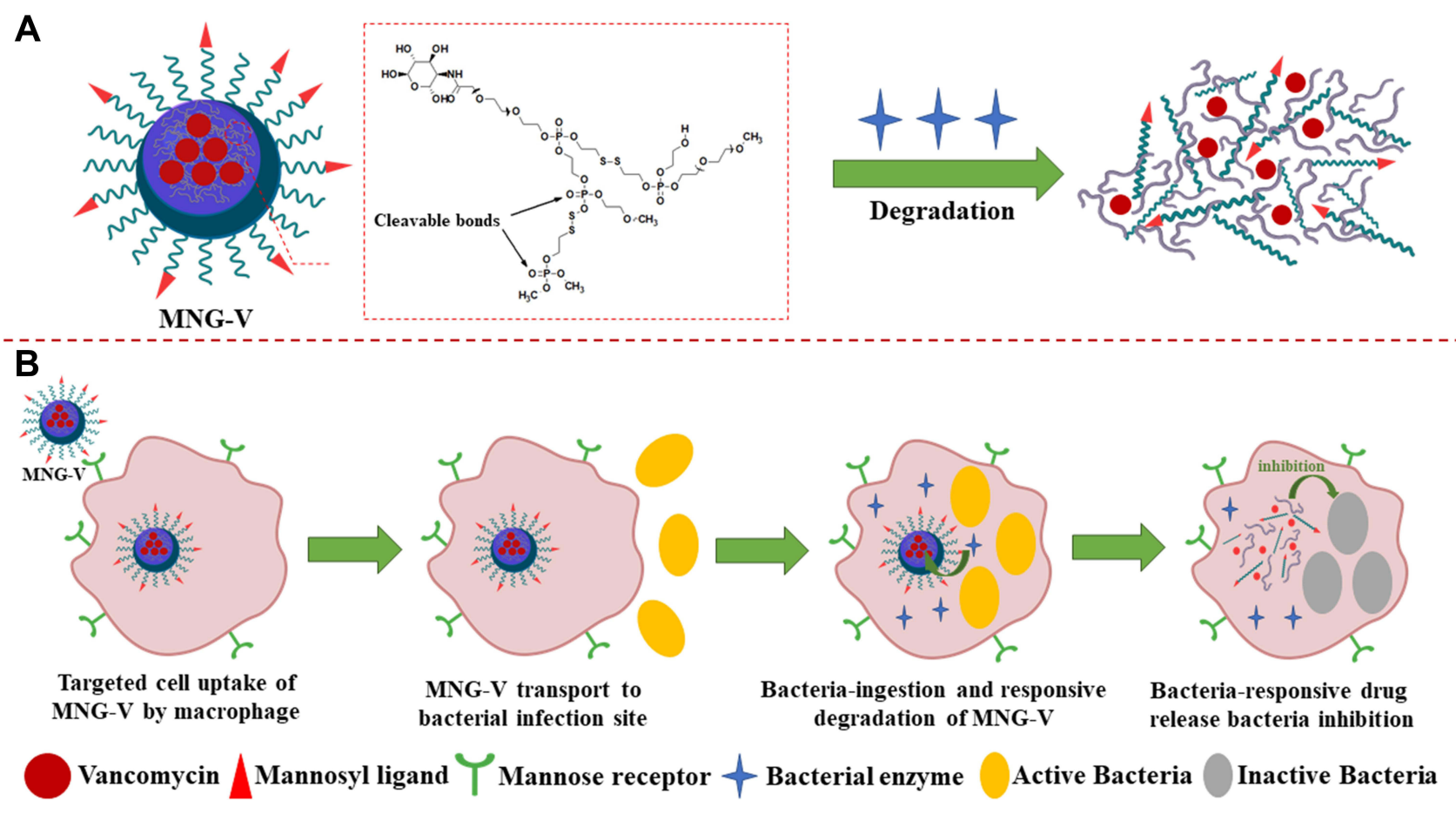

Figure 2 (A) Schematic illustration of a vancomycin-loaded mannosylated nanogels (MNG-V) can be degraded by bacteria secreting phosphatase or phospholipase. (B) Schematic illustration of targeted uptake of MNG-V, transport, degradation, drug release and bacteria inhibition.

loaded with vancomycin have an effect on methicillinresistant $S$. aureus (MRSA) and release drugs sufficiently to inhibit bacterial growth. ${ }^{1}$

\section{Enhance Macrophage Uptake with Novel Liposomes}

When conventional liposomes are intravenously injected, they are easily recognized by cells of the mononuclear phagocytic system (MPS), especially in the liver and spleen. Therefore, the targeted delivery of drugs to organs other than the liver and spleen and the role of conventional liposomes is limited. ${ }^{50}$

Sterically stabilized liposomes (SSLs) were then designed as drug delivery tools for mycobacterial infections. Unlike conventional liposomes, hydrophilic poly(ethylene) glycol (PEG) coating on the surface of the liposome can provide steric hindrance around the liposome, thereby reducing MPS rapid identification and uptake of cells. ${ }^{50,51}$ Therefore, SSLs could circulate blood for a relatively long period of time, creating the possibility of targeting infected tissues outside the liver and spleen. After long-term circulation in the blood, SSLs ooze out in infected tissues and eventually enter deep tissue macrophages, and SSLs can serve as a site-specific drug delivery system in mycobacterial infections.

\section{Transfection of Macrophages with Viruses for Specific Antibacterial Peptides}

Antimicrobial peptides exhibit potent antibacterial activity against a broad spectrum of pathogens, including intracellular bacteria, exhibiting strong lytic activity against both gram-positive and gram-negative bacteria, but are less cytotoxic to other cells in the human body. Therefore, a gene delivery system can be sought that enables cells to express antimicrobial peptides against antimicrobial infections. Compared to other gene transfer methods (retrovirus and cationic lipid), adenovirus does not depend on the state of cell division. In fact, normal macrophages can be efficiently transfected with viral and nonviral expression systems, and experiments have shown that adenoviruses can efficiently transfect macrophages. The adenovirus can then be recombined and can encode the hybrid antimicrobial peptide CAMA-syn encoding gene and the macrophage-specific promoter (MSP) into the adenovirus. The recombinant adenovirus-mediated antibacterial peptide CAMA-syn is expressed in macrophage and expresses the MSP promoter, showing macrophage antibacterial activity and macrophage specificity. It has been experimentally shown that CAMA-syn produced by an adenoviral vector can significantly increase the 
antibacterial activity against gram-positive and gramnegative bacterial strains. ${ }^{52}$

\section{Combined Treatment Strategy}

Nanomaterials are expected to enhance the therapeutic effect of bacterial infection because of their unique physical and chemical properties. ${ }^{53}$ Nanomaterials can not only kill bacteria alone but also perform a variety of germicidal pathways, making it difficult for bacteria to adapt to these treatments. These pathways depend on the shape and size of the core materials inherent in the nanomaterials and the modification groups and loaded antibacterial substances. Antimicrobial agents based on nanomedicine have proved the effectiveness of their bacterial infection. ${ }^{54}$ In this chapter, we mainly focus on the strategy of interaction between nanomedical materials and bacterial cells, which plays a key role in improving the therapeutic effect. ${ }^{55}$ According to the role of nanomaterials in antibacterial therapy, a new treatment strategy for bacterial infection was developed.

\section{Active Nanovectors Combined with Antibiotic Delivery}

Simultaneous delivery of active antibacterial nanoparticles and antibiotics is a promising combined antibacterial method. Stearylamine (SA) is a compound that can be used to target biofilm bacteria. ${ }^{56,57}$ Since the liposome of the cation-containing SA differs from the surface charge of the bacterial membrane or the negatively charged biofilm matrix compound, the liposome is bound to the bacterial cell membrane by electrostatic force. Experiments have demonstrated the attraction interaction between cationic liposomes mediated by electrostatic effects and negative potential points on the surface of bacteria or in extracellular mucus. $^{25,26}$ Liposomes composed of phosphatidylinositol (PI) and a small amount of dipalmitoylphosphatidylglycerol (DPPG) can also adsorb into biofilms formed by bacteria in the skin and oral cavity. The hydroxyl content of the inositol and glycerol heads in lipids plays an important role, and hydrogen bonds with teichoic acid may be formed in the sugar saccharides of the bacteria, allowing the liposomes to tightly bind to the bacterial biofilm and release antibiotics. $^{25,58}$

Not only liposomes, NPs can also be an effective choice for active carriers. Gu and his colleagues used this strategy to design mesoporous silica nanoparticles loaded with silver and levofloxacin (Ag@MSNs@LEVO) (Figure 3). ${ }^{59}$ The researchers prepared silver-coated mesoporous silica nanoparticles and then wrapped levofloxacin in the mesopores. The release of $\mathrm{Ag}^{+}$ions permeates the outer membrane of bacteria, making them more vulnerable to levofloxacin released at the same time. Drug-loaded nanoparticles showed synergistic effects on multidrug-resistant $E$. coli in vivo and in vitro. The antimicrobial activity of vancomycin-terminated AuNPs (Au@VanNPs) against vancomycin-resistant enterococci (VRE) and E. coli was 64 times higher than that of vancomycin itself, and ciprofloxacin-coated gold nanoparticles also had stronger anti-VRE activity. ${ }^{60}$ Different types of metals can be added to the same nanoparticles, so resistance to these nanoparticles will require the target microorganism to undergo several simultaneous mutations to become resistant to several metals. Nanoparticles containing both $\mathrm{TiO} 2$ and $\mathrm{Ag}$ ( $\mathrm{TiO} 2-\mathrm{Ag}$ nanoparticles) were found to be more effective against Candida albicans and Aspergillus albicans than individual Ag nanoparticles and fluconazole. ${ }^{61}$

With the development of materials science, there are still some antibacterial active materials become the research hotspot, such as antibacterial peptide-like oligomers. ${ }^{62}$ It can destroy the bacterial cell membrane, is not easy to produce drug resistance, and overcome the shortcomings of AMP being easily degraded by proteases in the body. ${ }^{63}$ The synergy of new materials and antibiotics can be used as one of the important antibacterial strategies.

\section{Combined Treatment Strategy of Photothermal Antibacterial and Photodynamic Antibacterial}

Photothermal antimicrobial activities, such as pasteurization, have been used as a physical antibacterial activity since before penicillin was discovered. It is believed that ordinary bacteria will be sterilized at temperatures above $55^{\circ} \mathrm{C}$ due to the denaturation of heat shock proteins. ${ }^{64}$ Therefore, people are expected to explore new methods of medical heat generation with high biocompatibility and high efficiency. In recent years, the photothermal effect of near-infrared light has been reported to have a high photothermal conversion efficiency. A series of photothermal nanomaterials have been developed to show strong light absorption ability to near-infrared light and convert light energy into thermal energy. The heat generated can inhibit the development of drug-resistant bacteria and prevent the formation of biofilm structure. ${ }^{65}$ Therefore, photothermal therapy (PTT) is considered to be a safe and effective strategy for the treatment of bacterial infections. Photothermal effect can also be 


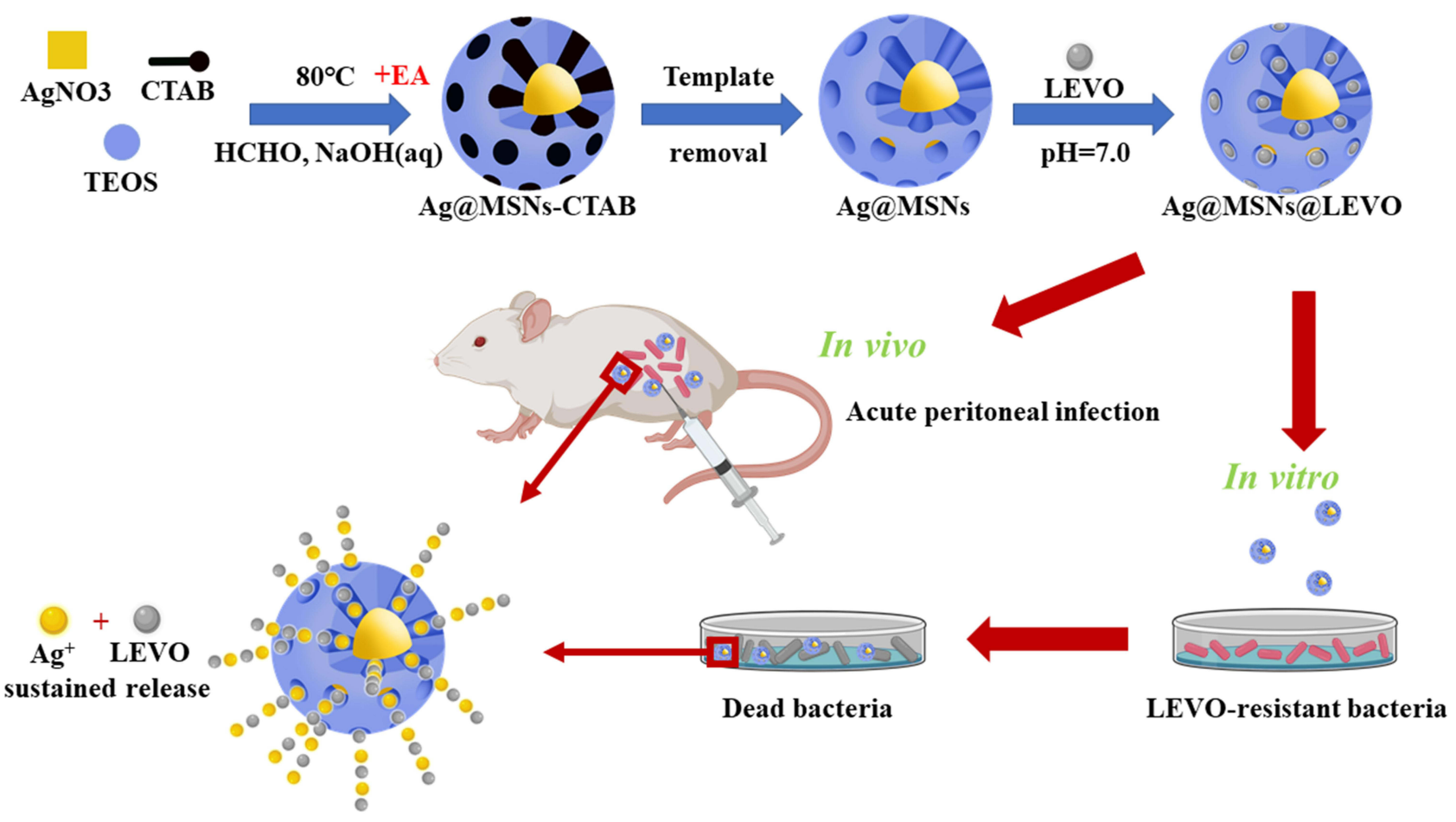

Figure 3 Schematic illustration of the fabrication of Ag@MSNs@LEVO nanoplatform and its application for a synergistic therapy of drug-resistant infections in vitro and in vivo. The silver core is the supplier of silver source, and the shell of mesoporous silica acts as the drug storage and release channel, which endows the single particle nanoplatform with the ability to release antibiotics and silver tower simultaneously.

combined with one or two other strategies to produce synergistic effect of antibacterial activity with better specificity and higher efficiency. ${ }^{66}$

Ding et al ${ }^{67}$ realized two-photon imaging, thermal generation, $\mathrm{Ag}^{+}$release and ROS production of bacteria using positively charged Au-Ag core-shell nanoparticles. S. aureus and $\mathrm{Au} @ \mathrm{Ag}$ nanoparticles were incubated for 4 minutes, and 92\% of the bacteria were killed under the irradiation of nearinfrared laser $(820 \mathrm{~nm})$. Another interesting example is the hybrid system of gold nanoparticles prepared by $\mathrm{Xu}$ et al (Figure 4) and polydopamine-assisted hydroxyapatite (PDA@Au-Hap). ${ }^{68}$ The authors point out that this nanomaterial can catalyze the formation of hydroxyl radicals $(\mathrm{OH})$ from low concentration $\mathrm{H}_{2} \mathrm{O}_{2}$ so as to improve the photothermal antibacterial properties of $45^{\circ} \mathrm{C}$ and avoid unnecessary damage to normal tissue. In addition to sterilization, it can also promote the formation of granulation tissue and the synthesis of collagen, and accelerate wound healing. Some conjugated polymers are used to prepare antibacterial nanomaterials with photothermal effect. Two typical examples are Polyaniline (PANI) and poly (3pyr4-ethylenedioxythiophene) (PEDOT). $\mathrm{Li}$ et al coated indocyanine green (ICG) on PEDOT nanoparticles by electrostatic attraction, and further coupled it with PEG and glutaraldehyde (GTA) to obtain bacterial targeting. ${ }^{69}$
A special feature of these PEDOT: ICG@PEG-GTA nanoparticles is that ICG can produce reactive oxygen species in near infrared region I (808Nm), while PEDOT shows strong absorption in near infrared region II (1064Nm), thus forming dual-mode PDT/PTT. They have high photothermal conversion efficiency (71.1\%), excellent photostability, low toxicity and good germicidal efficacy (99\%).

Dopamine (PDA) has also attracted wide attention recently because it can modify the surface of various materials. It has also been proved to be a photothermal conversion agent. ${ }^{70} \mathrm{Fe}_{3} \mathrm{O}_{4} @$ PDA nanoparticles were synthesized by Liu et al loaded with heat shock protein 70 (HSP70) inhibitor 2-phenylethyne sulfonamide (PES), to form a new type of synergistic antibacterial application nano-platform. Under the irradiation of near-infrared laser, PES can be released from PDA@ $\mathrm{Fe}_{3} \mathrm{O}_{4}+\mathrm{PES}$ nanoparticles, and specifically interfere with the HSP70, on the surface of bacteria to reduce the tolerance of bacteria to thermal damage, so as to improve the germicidal efficacy. ${ }^{71} \mathrm{Yu}$ et al also used $\mathrm{Fe}_{3} \mathrm{O}_{4} @$ PDA nanoparticles. ${ }^{72}$ As the core of the third generation dendritic poly (amide-amine) (PAMAM-G3) grafted, the prepared $\mathrm{Fe}_{3} \mathrm{O}_{4} @$ PDA@PMAA@PAMAM nanoparticles showed controllable NO release under near-infrared laser irradiation. The synergistic effect of light and heat 


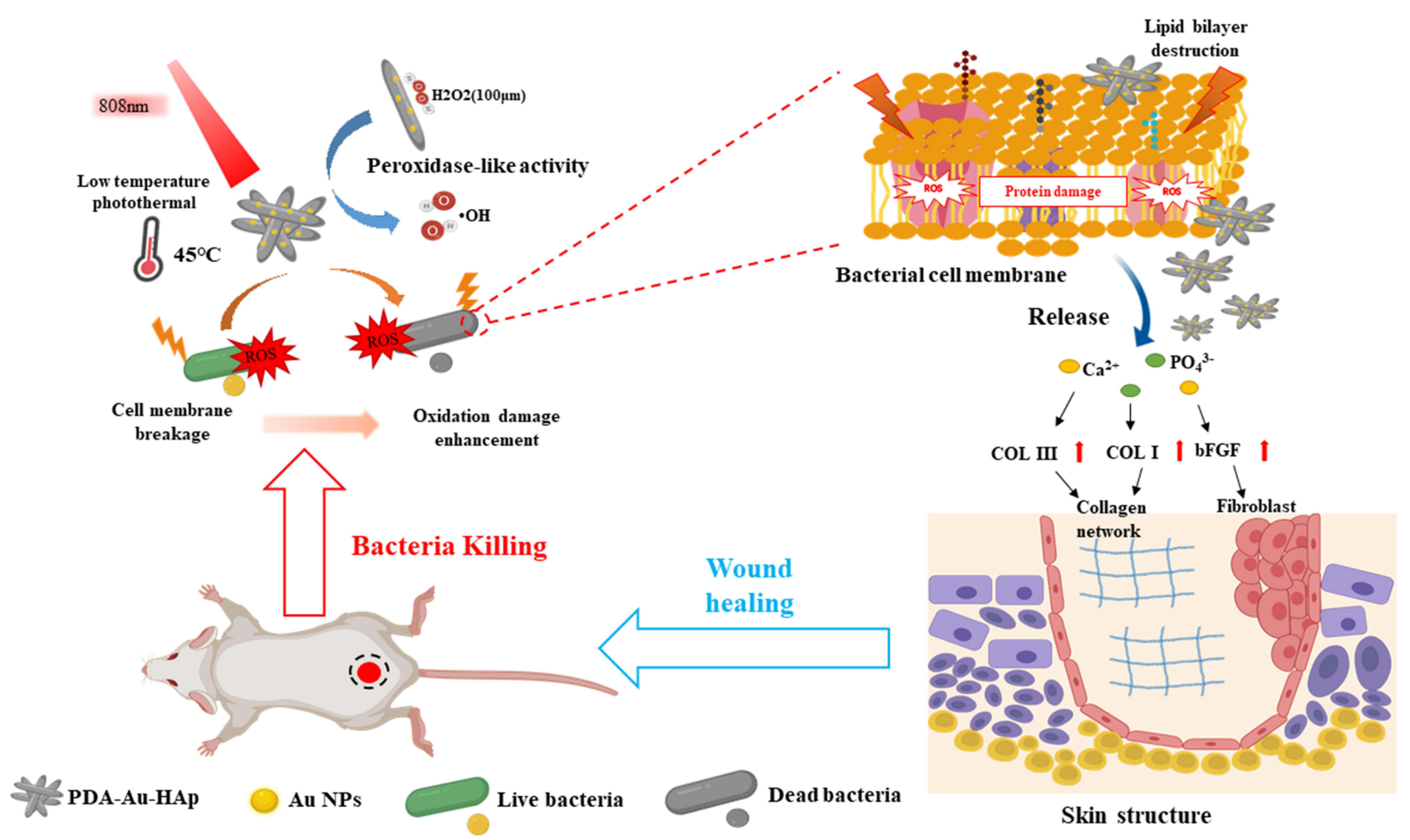

Figure 4 Schematic illustration of photothermal therapy combined with catalysis to achieve antibacterial effects and promote wound healing in vivo. PDA@Au-HAp catalyze the formation of $\mathrm{OH}$ from $\mathrm{H}_{2} \mathrm{O}_{2}$ at low concentration, enhanced photothermal antibacterial performance at $45^{\circ} \mathrm{C}$ via destruct cell membranes, proteins and DNA, PDA and the release of $\mathrm{Ca}^{2+}$ and $\mathrm{PO}_{4}{ }^{3-}$ promote the expression of related genes in $\mathrm{NIH} 3 \mathrm{~T} 3$ cells, facilitate the formation of granulation tissue and collagen synthesis to accelerate wound healing.

had no bacteriostatic effect on E. coli and S. aureus, but the bacterial activity and biofilm biomass decreased significantly. ${ }^{65}$

\section{Combination of Photothermal and Antibacterial Delivery of Antibiotics}

Meeker et al (Figure 5) constructed a gold nanocage and modified it with daptomycin and staphylococcal protein antibodies. ${ }^{73}$ These nano-cages can be specifically anchored on the surface of $S$. aureus and produce high temperatures under near-infrared radiation. When heated, daptomycin is released, creating a synergistic chemical-photothermal effect to kill $S$. aureus. After the initial near-infrared irradiation, the germicidal effect was still significant after being placed in the dark for 24 hours. Thermosensitive liposomes have antibacterial activity by synergistic chemical-photothermal therapy. ${ }^{74,75}$ We designed and prepared near-infrared activated thermosensitive liposomes with the ability of photothermal and antibiotic synergistic therapy to eliminate $P$. aeruginosa biofilm. Positively charged and small liposomes help to enter the biofilm microchannel and release antibiotics locally at the infection site. Liposomes can remain stable at $37^{\circ} \mathrm{C}$ and release about $80 \%$ antibiotics at $45^{\circ} \mathrm{C}$. The biofilm dispersion rate is as high as $80 \%$, an increase of 7 to 8 times compared with excessive antibiotics alone, indicating that local antibiotic release and photothermal combination therapy have improved antibacterial efficiency. Drug-loaded liposomes show outstanding therapeutic effect in the treatment of abscess caused by $P$. aeruginosa. This chemical-photothermal therapy can effectively ablate bacteria with low doses of antibiotics.

\section{Conclusions and Outlook}

Bacterial resistance caused by the widespread use of antibiotics has set the application of antibiotics in antimicrobial infections in a dilemma. New strategies are urgently needed to improve the pharmacokinetic and nanocarrierenriched antibiotics at the infection site by means of different drug delivery strategies, which not only improves the antibacterial effect of antibiotics but also helps to reduce the possibility of bacterial drug resistance. This review introduces three targeting strategies based on the pathological characteristics of the bacterial infection site and some combined treatment strategies. 


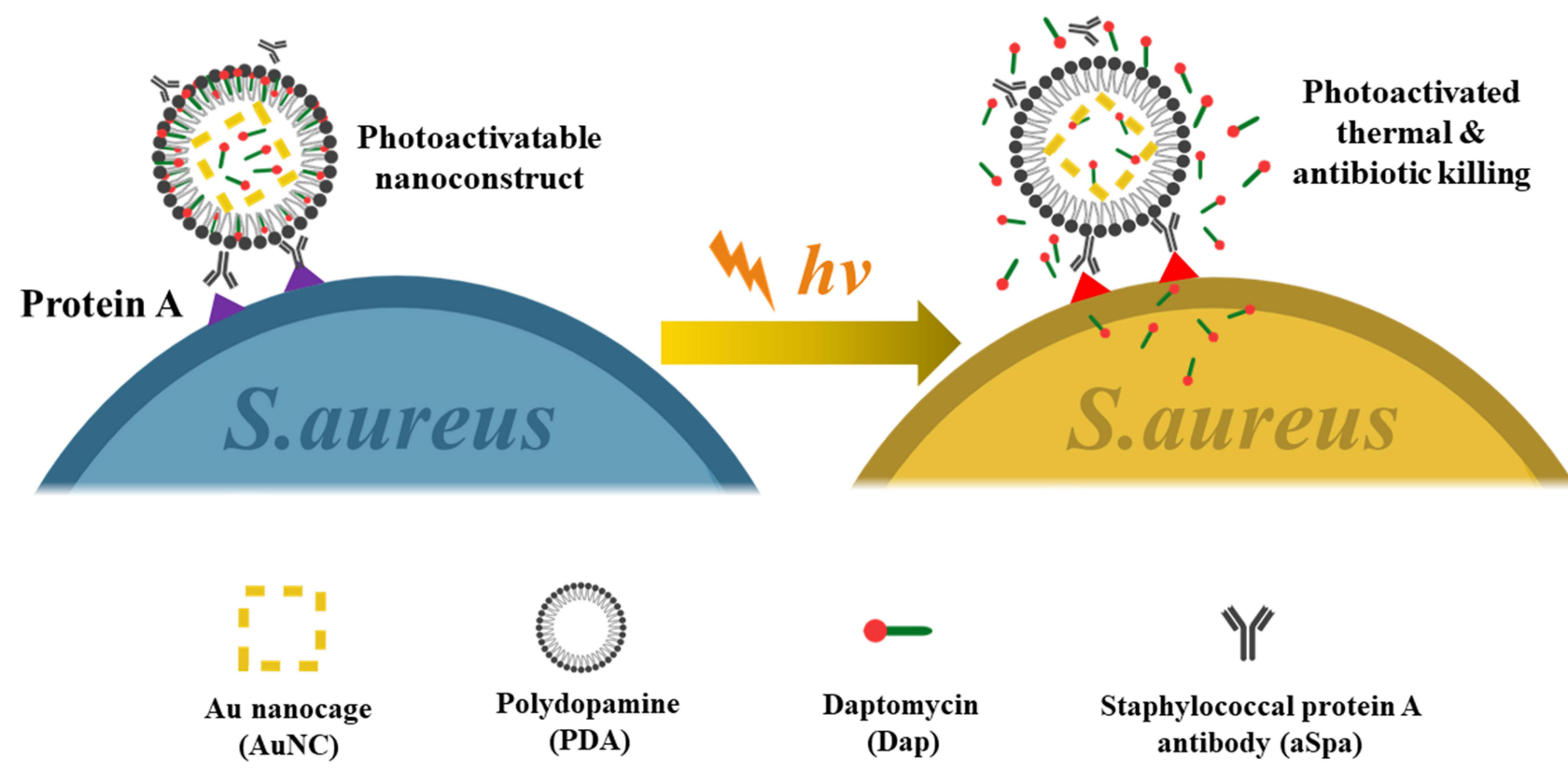

Figure 5 Schematic illustration of the working mechanism of the targeted photoactivatable nano-construct for synergistic photothermal and antibiotic treatment of S. aureus.

The application of conventional antibiotics is in a dilemma, such as poor efficacy against drug-resistant bacteria, low therapeutic index, high cytotoxicity and side effects. Fortunately, these drawbacks can be compensated to some extent using various antimicrobial drug delivery system involving nanotechnology. Nanocarriers have small size, high surface-to-volume ratio and are amenable to surface modification, which can bind the receptor or respond to environmental stimuli. So, antibiotics could be accurately released to the site of infection, thereby increasing drug concentration and reducing the side effects of antibiotics in non-infected tissues. Targeted drug delivery using nanocarriers can not only achieve better antibacterial effects by using decreased drug dose but also inhibit the generation of bacterial resistance.

The future development of nano-antibacterial strategies may still focus on the multiple combined treatment, especially the combination of the nanovectors with antibacterial activities (such as cationic liposomes, metal nanoparticles, dendrimers and graphene, et al) and antibiotics or antimicrobial peptide (AMP), making the nano drug delivery system more intelligent and have better application prospects. Since these carriers have certain antibacterial capacities, such as production of ROS, the combination of the two may have synergistic antibacterial effects on the basis of ensuring accurate drug delivery.
In addition, biological vectors (such as viral, lysozymes, biomimetic vectors, et al) also offer many significant advantages compared with abiotic vectors. Viral vectors, especially phages, can autonomously target bacteria by virtue of their own specific proteins. And lysozyme, since it is an antimicrobial enzyme, has effective bactericidal activity against most pathogens. In addition, biological vectors have high transfection efficiency, and thus serve as an ideal vehicle for large molecules, such as genes and polypeptides. These advantages make the biological carriers more worthy of further study.

Although antibacterial carriers have entered the era of nanotechnology, these targeted drug delivery systems still face many challenges, such as carrier stability, safety, and biocompatibility. In the future, with the further research of DDS theory targeted drug delivery system will be gradually improved and be more widely used in antimicrobial therapy.

\section{Acknowledgments}

This work was supported by grants from the National Science and Technology Major Project (No. 2017YFA0205400) and the National Science Foundation Grant of China (No. 81503005); Six Talent Peak Project in Jiangsu Province (No. SWYY-106); the Priority Academic Program Development of Jiangsu Higher Education Institutions. 


\section{Disclosure}

The authors declare no conflicts of interest in this work.

\section{References}

1. Xiong MH, Li YJ, Bao Y, Yang XZ, Hu B, Wang J. Bacteriaresponsive multifunctional nanogel for targeted antibiotic delivery. Adv Mater. 2012;24(46):6175-6180. doi:10.1002/adma.201202847

2. Ohta S. Molecular hydrogen as a novel antioxidant: overview of the advantages of hydrogen for medical applications. Methods Enzymol. 2015;555:289-317.

3. Hu CM, Fang RH, Wang KC, et al. Nanoparticle biointerfacing by platelet membrane cloaking. Nature. 2015;526(7571):118-121. doi:10.1038/nature15373

4. Thamphiwatana S, Gao W, Pornpattananangkul D, et al. Phospholipase A2-responsive antibiotic delivery via nanoparticle-stabilized liposomes for the treatment of bacterial infection. J Mater Chem B Mater Biol Med. 2014;2(46):8201-8207. doi:10.1039/C4TB01110D

5. Zheng K, Li K, Chang TH, Xie J, Chen PY. Synergistic antimicrobial capability of magnetically oriented graphene oxide conjugated with gold nanoclusters. Adv Funct Mater. 2019;29:46.

6. Tezel BU, Akçelik N, Yüksel FN, Karatuğ NT, Akçelik M. Effects of sub-MIC antibiotic concentrations on biofilm production of Salmonella infantis. Biotechnol Biotechnol Equip. 2016;30 (6):1184-1191. doi:10.1080/13102818.2016.1224981

7. Re ACS, Martins JF, Cunha-Filho M, Gelfuso GM, Aires CP, Gratieri T. New perspectives on the topical management of recurrent candidiasis. Drug Deliv Transl Res. 2021;11(4):1568-1585. doi:10.1007/s13346-021-00901-0

8. Si Y, Grazon C, Clavier G, et al. Rapid and accurate detection of Escherichia coli growth by fluorescent $\mathrm{pH}$-sensitive organic nanoparticles for high-throughput screening applications. Biosens Bioelectron. 2016;75:320-327. doi:10.1016/j.bios.2015.08.028

9. Radovic-Moreno AF, Lu TK, Puscasu VA, Yoon CJ, Langer R, Farokhzad OC. Surface charge-switching polymeric nanoparticles for bacterial cell wall-targeted delivery of antibiotics. ACS Nano. 2012;6(5):4279-4287. doi:10.1021/nn3008383

10. Wang B, Liu H, Wang Z, et al. A self-defensive antibacterial coating acting through the bacteria-triggered release of a hydrophobic antibiotic from layer-by-layer films. $J$ Mater Chem B. 2017;5 (7):1498-1506. doi:10.1039/C6TB02614A

11. Zhuk I, Jariwala F, Attygalle AB, Wu Y, Libera MR, Sukhishvili SA. Self-defensive layer-by-layer films with bacteria-triggered antibiotic release. ACS Nano. 2014;8(8):7733-7745. doi:10.1021/nn500674g

12. Arif M, Dong QJ, Raja MA, Zeenat S, Chi Z, Liu CG. Development of novel $\mathrm{pH}$-sensitive thiolated chitosan/PMLA nanoparticles for amoxicillin delivery to treat Helicobacter pylori. Mater Sci Eng C. 2018;83:17-24. doi:10.1016/j.msec.2017.08.038

13. Thamphiwatana S, Fu V, Zhu J, Lu D, Gao W, Zhang L. Nanoparticle-stabilized liposomes for $\mathrm{pH}$-responsive gastric drug delivery. Langmuir. 2013;29(39):12228-12233. doi:10.1021/ la $402695 \mathrm{c}$

14. Ferguson EL, Azzopardi E, Roberts JL, Walsh TR, Thomas DW. Dextrin-colistin conjugates as a model bioresponsive treatment for multidrug resistant bacterial infections. Mol Pharm. 2014;11 (12):4437-4447. doi:10.1021/mp500584u

15. Hirst D, German L, Duncan R. Dextrins as carriers for drug targeting: reproducible succinoylation as a means to introduce pendant groups. J Bioact Compat Polym. 2001;16(5):353-365. doi:10.1106/QBKYE3VM-19K4-3GA5

16. Hreczuk-Hirst D, Chicco D, German L, Duncan R. Dextrins as potential carriers for drug targeting: tailored rates of dextrin degradation by introduction of pendant groups. Int J Pharm. 2001;230(12):57-66. doi:10.1016/S0378-5173(01)00859-6
17. Xiong MH, Bao Y, Yang XZ, Wang YC, Sun B, Wang J. Lipasesensitive polymeric triple-layered nanogel for "on-demand" drug delivery. J Am Chem Soc. 2012;134(9):4355-4362. doi:10.1021/ ja2 $11279 \mathrm{u}$

18. London E. How bacterial protein toxins enter cells; the role of partial unfolding in membrane translocation. Mol Microbiol. 1992;6 (22):3277-3282. doi:10.1111/j.1365-2958.1992.tb02195.x

19. Menestrina G, Pederzolli C, Forti S, Gambale F. Lipid interaction of Pseudomonas aeruginosa exotoxin A. Acid-triggered permeabilization and aggregation of lipid vesicles. Biophys J. 1991;60 (6):1388-1400. doi:10.1016/S0006-3495(91)82176-2

20. Olsnes S, Sandvig K. How protein toxins enter and kill cells. Cancer Treat Res. 1988;37:39-73.

21. Pornpattananangkul D, Zhang L, Olson S, et al. Bacterial toxin-triggered drug release from gold nanoparticle-stabilized liposomes for the treatment of bacterial infection. $J$ Am Chem Soc. 2011;133(11):4132-4139. doi:10.1021/ja111110e

22. Yang S, Han X, Yang Y, et al. Bacteria-targeting nanoparticles with microenvironment-responsive antibiotic release to eliminate intracellular staphylococcus aureus and associated infection. ACS Appl Mater Interfaces. 2018;10(17):14299-14311. doi:10.1021/ acsami.7b15678

23. Khin MM, Hua JS, Ng HC, Wadstrom T, Bow H. Agglutination of Helicobacter pylori coccoids by lectins. World $J$ Gastroenterol. 2000;6(2):202-209.

24. Umamaheshwari RB, Jain NK. Receptor mediated targeting of lectin conjugated gliadin nanoparticles in the treatment of Helicobacter pylori. J Drug Target. 2003;11(7):415-423; discussion 423-414. doi:10.1080/10611860310001647771

25. Forier K, Raemdonck K, De Smedt SC, Demeester J, Coenye T, Braeckmans K. Lipid and polymer nanoparticles for drug delivery to bacterial biofilms. $J$ Control Release. 2014;190:607-623. doi:10.1016/j.jconrel.2014.03.055

26. Sihorkar V, Vyas SP. Biofilm consortia on biomedical and biological surfaces: delivery and targeting strategies. Pharm Res. 2001;18 (9):1247-1254. doi:10.1023/A:1013073508318

27. Long Y, Li Z, Bi Q, et al. Novel polymeric nanoparticles targeting the lipopolysaccharides of Pseudomonas aeruginosa. Int J Pharm. 2016;502 (1-2):232-241. doi:10.1016/j.ijpharm.2016.02.021

28. Li L, Lu Y, Bie Z, Chen HY, Liu Z. Photolithographic boronate affinity molecular imprinting: a general and facile approach for glycoprotein imprinting. Angew Chem Int Ed. 2013;52 (29):7451-7454. doi:10.1002/anie.201207950

29. Zeng Z, Hoshino Y, Rodriguez A, Yoo H, Shea KJ. Synthetic polymer nanoparticles with antibody-like affinity for a hydrophilic peptide. ACS Nano. 2010;4(1):199-204. doi:10.1021/nn901256s

30. Pan G, Guo Q, Ma Y, Yang H, Li B. Thermo-responsive hydrogel layers imprinted with RGDS peptide: a system for harvesting cell sheets. Angew Chem Int Ed. 2013;52(27):6907-6911. doi:10.1002/ anie. 201300733

31. Kang SJ, Park SJ, Mishig-Ochir T, Lee BJ. Antimicrobial peptides: therapeutic potentials. Expert Rev Anti Infect Ther. 2014;12 (12):1477-1486. doi:10.1586/14787210.2014.976613

32. Mohtashamian S, Boddohi S. Nanostructured polysaccharide-based carriers for antimicrobial peptide delivery. J Pharmaceut Invest. 2017;47(2):85-94. doi:10.1007/s40005-016-0289-1

33. Kim H, Jang JH, Kim SC, Cho JH. Enhancement of the antimicrobial activity and selectivity of GNU7 against Gram-negative bacteria by fusion with LPS-targeting peptide. Peptides. 2016;82:60-66. doi:10.1016/j.peptides.2016.05.010

34. Braun V, Götz F, Schultz JE, Wohlleben W. The bacterial cell envelope: structure, function, and infection interface. Int J Med Microbiol. 2015;305(2):175-177. doi:10.1016/j.ijmm.2014.12.003

35. Malanovic N, Lohner K. Gram-positive bacterial cell envelopes: the impact on the activity of antimicrobial peptides. Biochim Biophys Acta. 2016;1858(5):936-946. doi:10.1016/j.bbamem.2015.11.004 
36. Ogundele MO. A novel anti-inflammatory activity of lysozyme: modulation of serum complement activation. Mediators Inflamm. 1998;7(5):363-365. doi:10.1080/09629359890893

37. Ibrahim HR. New drug-targeting strategy from beneath the shell of egg. Expert Opin Drug Deliv. 2010;7(10):1145-1158. doi:10.1517/ 17425247.2010.515208

38. Luo M, Jia YY, Jing ZW, et al. Construction and optimization of $\mathrm{pH}$-sensitive nanoparticle delivery system containing PLGA and UCCs-2 for targeted treatment of Helicobacter pylori. Colloids Surf B Biointerfaces. 2018;164:11-19. doi:10.1016/j.colsurfb.2018.01.008

39. Jing ZW, Jia YY, Wan N, et al. Design and evaluation of novel pH-sensitive ureido-conjugated chitosan/TPP nanoparticles targeted to Helicobacter pylori. Biomaterials. 2016;84:276-285. doi:10.1016/ j.biomaterials.2016.01.045

40. Fallon PG, Alcami A. Pathogen-derived immunomodulatory molecules: future immunotherapeutics? Trends Immunol. 2006;27 (10):470-476. doi:10.1016/j.it.2006.08.002

41. Alvarez-Lorenzo C, Garcia-Gonzalez CA, Bucio E, Concheiro A. Stimuli-responsive polymers for antimicrobial therapy: drug targeting, contact-killing surfaces and competitive release. Expert Opin Drug Deliv. 2016;13(8):1109-1119. doi:10.1080/17425247.2016. 1178719

42. Sharma A, Kumar Arya D, Dua M, Chhatwal GS, Johri AK. Nanotechnology for targeted drug delivery to combat antibiotic resistance. Expert Opin Drug Deliv. 2012;9(11):1325-1332. doi:10.1517/ 17425247.2012.717927

43. Mudakavi R, Vanamali S, Chakravortty D, Raichur A. Development of arginine based nanocarriers for targeting and treatment of intracellular Salmonella. RSC Adv. 2017;7(12):7022-7032. doi:10.1039/ C6RA27868J

44. Chono S, Tanino T, Seki T, Morimoto K. Efficient drug targeting to rat alveolar macrophages by pulmonary administration of ciprofloxacin incorporated into mannosylated liposomes for treatment of respiratory intracellular parasitic infections. $J$ Control Release. 2008;127(1):50-58. doi:10.1016/j.jconrel.2007.12.011

45. Sinha J, Mukhopadhyay S, Das N, Basu MK. Targeting of liposomal andrographolide to L. donovani-infected macrophages in vivo. Drug Deliv. 2000;7(4):209-213. doi:10.1080/107175400455137

46. Chono S, Tanino T, Seki T, Morimoto K. Uptake characteristics of liposomes by rat alveolar macrophages: influence of particle size and surface mannose modification. J Pharm Pharmacol. 2007;59 (1):75-80. doi:10.1211/jpp.59.1.0010

47. Nimje N, Agarwal A, Saraogi GK, et al. Mannosylated nanoparticulate carriers of rifabutin for alveolar targeting. J Drug Target. 2009;17(10):777-787. doi:10.3109/10611860903115308

48. Chono S, Kaneko K, Yamamoto E, Togami K, Morimoto K. Effect of surface-mannose modification on aerosolized liposomal delivery to alveolar macrophages. Drug Dev Ind Pharm. 2010;36(1):102-107. doi:10.3109/03639040903099744

49. Lee WH, Loo CY, Traini D, Young PM. Nano- and micro-based inhaled drug delivery systems for targeting alveolar macrophages. Expert Opin Drug Deliv. 2015;12(6):1009-1026. doi:10.1517/ 17425247.2015.1039509

50. de Steenwinkel JE, van Vianen W, Ten Kate MT, et al. Targeted drug delivery to enhance efficacy and shorten treatment duration in disseminated Mycobacterium avium infection in mice. $J$ Antimicrob Chemother. 2007;60(5):1064-1073. doi:10.1093/jac/dkm341

51. Woodle MC. Sterically stabilized liposome therapeutics. Adv Drug Deliv Rev. 1995;16(2):249-265. doi:10.1016/0169-409X(95)00028-6

52. Zhang J, Xie L, Xu D, et al. Targeting expression of antimicrobial peptide CAMA-Syn by adenovirus vector in macrophages inhibits the growth of intracellular bacteria. Gene. 2017;630:59-67. doi:10.1016/ j.gene.2017.07.079

53. Hajipour MJ, Fromm KM, Ashkarran AA, et al. Antibacterial properties of nanoparticles. Trends Biotechnol. 2012;30(10):499-511. doi:10.1016/j.tibtech.2012.06.004
54. Gupta A, Landis RF, Rotello VM. Nanoparticle-based antimicrobials: surface functionality is critical. F1000Research. 2016;5:1-10. doi:10.12688/f1000research.7595.1

55. Miller KP, Wang L, Benicewicz BC, Decho AW. Inorganic nanoparticles engineered to attack bacteria. Chem Soc Rev. 2015;44 (21):7787-7807.

56. Jones MN, Song YH, Kaszuba M, Reboiras MD. The interaction of phospholipid liposomes with bacteria and their use in the delivery of bactericides. J Drug Target. 1997;5(1):25-34. doi:10.3109/ 10611869708995855

57. Jones MN, Kaszuba M, Hill KJ, Song YH, Creeth JE. The use of phospholipid liposomes for targeting to oral and skin-associated bacteria. J Drug Target. 1994;2(5):381-389. doi:10.3109/ 10611869408996813

58. Jones MN, Kaszuba M, Reboiras MD, et al. The targeting of phospholipid liposomes to bacteria. Biochim Biophys Acta. 1994;1196 (1):57-64. doi:10.1016/0005-2736(94)90295-X

59. Wang Y, Ding X, Chen Y, et al. Antibiotic-loaded, silver core-embedded mesoporous silica nanovehicles as a synergistic antibacterial agent for the treatment of drug-resistant infections. Biomaterials. 2016;101:207-216. doi:10.1016/j.biomaterials.2016.06.004

60. Huh AJ, Kwon YJ. "Nanoantibiotics": a new paradigm for treating infectious diseases using nanomaterials in the antibiotics resistant era. $J$ Control Release. 2011;156(2):128-145.

61. Blecher K, Nasir A, Friedman A. The growing role of nanotechnology in combating infectious disease. Virulence. 2011;2(5):395-401. doi:10.4161/viru.2.5.17035

62. Christofferson AJ, Elbourne A, Cheeseman S, et al. Conformationally tuned antibacterial oligomers target the peptidoglycan of gram-positive bacteria. J Colloid Interface Sci. 2020;580:850-862. doi:10.1016/j.jcis.2020.07.090

63. Im BN, Shin H, Lim B, et al. Helicobacter pylori-targeting multiligand photosensitizer for effective antibacterial endoscopic photodynamic therapy. Biomaterials. 2021;271:120745. doi:10.1016/j. biomaterials.2021.120745

64. Pan WY, Huang CC, Lin TT, et al. Synergistic antibacterial effects of localized heat and oxidative stress caused by hydroxyl radicals mediated by graphene/iron oxide-based nanocomposites. Nanomedicine. 2016;12(2):431-438. doi:10.1016/j.nano.201 5.11 .014

65. Jaque D, Martínez Maestro L, Del Rosal B, et al. Nanoparticles for photothermal therapies. Nanoscale. 2014;6(16):9494-9530.

66. Xu JW, Yao K, Xu ZK. Nanomaterials with a photothermal effect for antibacterial activities: an overview. Nanoscale. 2019;11 (18):8680-8691. doi:10.1039/C9NR01833F

67. Ding X, Yuan P, Gao N, Zhu H, Yy Y, Qh X. Au-Ag core-shell nanoparticles for simultaneous bacterial imaging and synergistic antibacterial activity. Nanomedicine. 2017;13(1):297-305. doi:10.1016/j. nano.2016.09.003

68. Xu X, Liu X, Tan L, et al. Controlled-temperature photothermal and oxidative bacteria killing and acceleration of wound healing by polydopamine-assisted Au-hydroxyapatite nanorods. Acta Biomater. 2018;77:352-364. doi:10.1016/j.actbio.2018.07.030

69. Li L, Liu Y, Hao P, et al. PEDOT nanocomposites mediated dual-modal photodynamic and photothermal targeted sterilization in both NIR I and II window. Biomaterials. 2015;41:132-140. doi:10.1016/j.biomaterials.2014.10.075

70. Qiu WZ, Yang HC, Xu ZK. Dopamine-assisted co-deposition: an emerging and promising strategy for surface modification. $A d v$ Colloid Interface Sci. 2018;256:111-125. doi:10.1016/j. cis.2018.04.011

71. Liu D, Ma L, Liu L, et al. Polydopamine-encapsulated Fe3O4 with an adsorbed HSP70 inhibitor for improved photothermal inactivation of bacteria. ACS Appl Mater Interfaces. 2016;8(37):24455-24462. doi:10.1021/acsami.6b08119 
72. Yu L, Luo B, Li Z, He J, Lan F, Wu Y. PAMAM-PMAA brush-functionalized magnetic composite nanospheres: a smart nanoprobe with tunable selectivity for effective enrichment of mono-, multi-, or global phosphopeptides. J Mater Chem B. 2020;8 (6):1266-1276. doi:10.1039/C9TB02577D

73. Meeker DG, Jenkins SV, Miller EK, et al. Synergistic photothermal and antibiotic killing of biofilm-associated staphylococcus aureus using targeted antibiotic-loaded gold nanoconstructs. ACS Infect Dis. 2016;2(4):241-250. doi:10.1021/acsinfecdis.5b00117
74. Zhao Y, Dai X, Wei X, et al. Near-infrared light-activated thermosensitive liposomes as efficient agents for photothermal and antibiotic synergistic therapy of bacterial biofilm. ACS Appl Mater Interfaces. 2018;10(17):14426-14437. doi:10.1021/acsami.8b01327

75. Zhang L, Wang Y, Wang J, et al. Photon-responsive antibacterial nanoplatform for synergistic photothermal-/pharmaco-therapy of skin infection. ACS Appl Mater Interfaces. 2019;11(1):300-310. doi:10.1021/acsami.8b18146

\section{Publish your work in this journal}

The International Journal of Nanomedicine is an international, peerreviewed journal focusing on the application of nanotechnology in diagnostics, therapeutics, and drug delivery systems throughout the biomedical field. This journal is indexed on PubMed Central, MedLine, CAS, SciSearch ${ }^{\mathbb{R}}$, Current Contents ${ }^{\mathbb{R}} /$ Clinical Medicine, $^{-}$
Journal Citation Reports/Science Edition, EMBase, Scopus and the Elsevier Bibliographic databases. The manuscript management system is completely online and includes a very quick and fair peer-review system, which is all easy to use. Visit http://www.dovepress.com/ testimonials.php to read real quotes from published authors. 